INTERNATIONAL CONGRESS OF EGYPTOLOGISTS XI

Florence, Italy 23 - 30 August 2015

MUSEO EGIZIO FIRENZE FLORENCE EGYPTIAN MUSEUM

\title{
Basic considerations on the construction of
}

\section{Pyramids in the Old Kingdom}

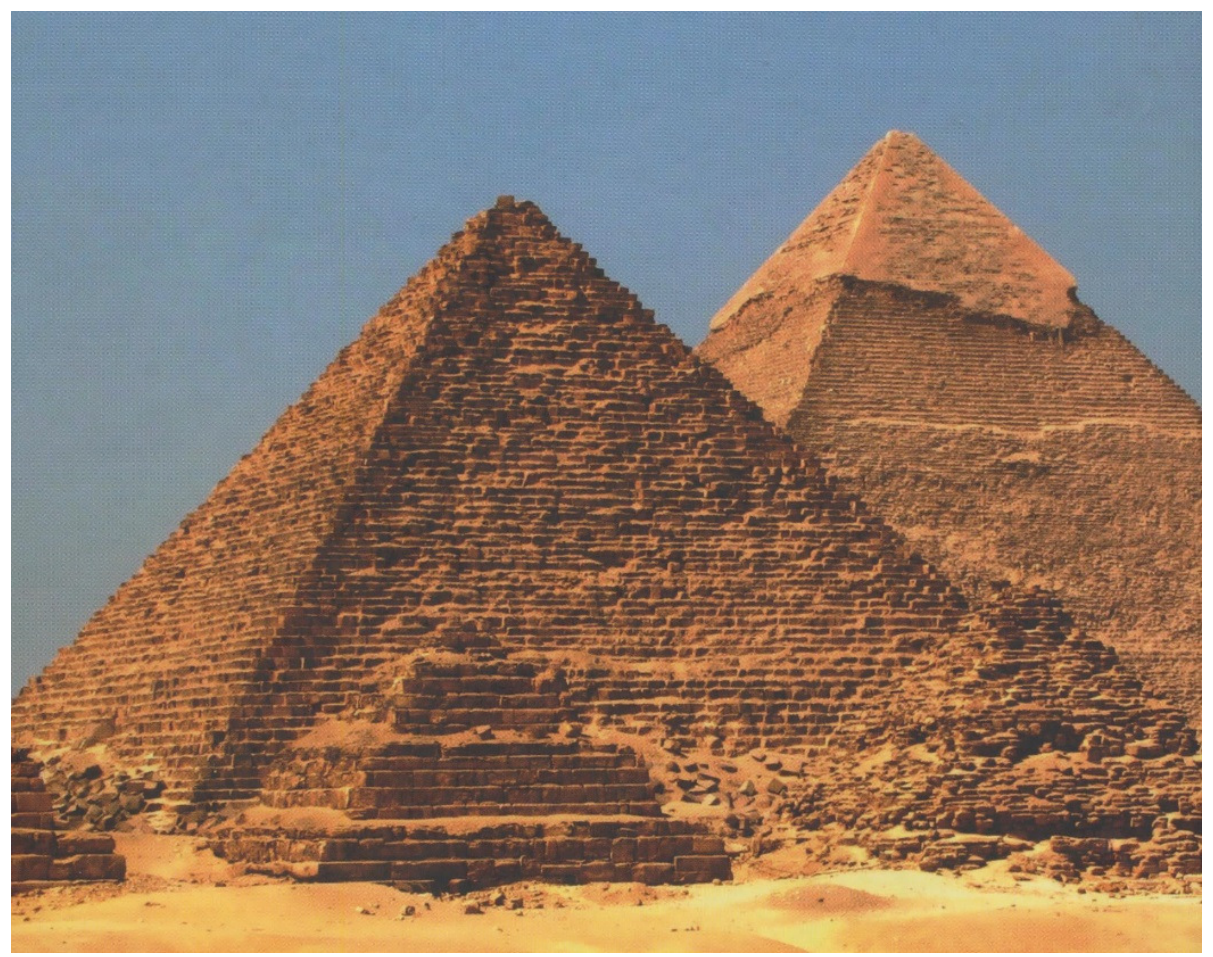




\title{
Basic considerations on the construction of pyramids in the Old Kingdom
}

\author{
International Congress of Egyptologists XI
}

Over the years there have been many hypotheses concerning the construction of the pyramids in the ancient Egypt - amongst others from well-known Egyptologists. In this paper some basic considerations and conclusions will be introduced and the hypothesis will be discussed that have so far been brought forward. Based on this, a solution will be presented for the problem of the construction of the pyramids in the Old Kingdom.

\section{Introduction}

Life expectancy in Ancient Egypt was on average 35 years. Despite the relatively high standard of medical care many inflammations, especially as a result of injury, were fatal. Even in living conditions with above-average hygienic standards, excellent medical care and a good diet, kings and high-ranking officials were still affected by suddenly occurring fatal illnesses.

Of twenty-two kings of the 3rd to the 6th dynasty who built pyramids, at least six died before the completion of their tombs: Sekhemkhet, Khaba, Djedefre, Bikheris, Shepseskare and Neferefre.

It can thus be assumed that upon accession every king arranged for his pyramid to be planned, built and completed as soon as possible. Therefore, as short a construction time as possible determined the construction method used. This was the highest priority for the construction of the pyramid.

\section{Basic considerations and preliminary conclusions}

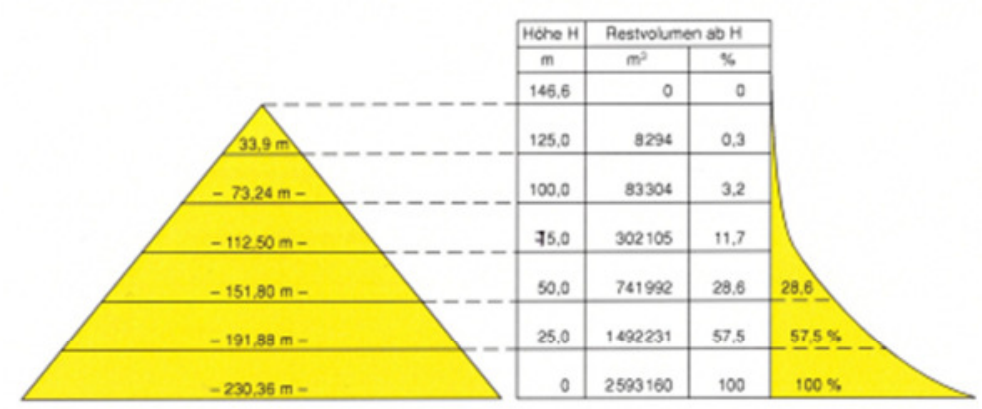

Amount of stones needed according to height of pyramid - using the example of the Pyramid of Khufu/Cheops.

$70 \%$ of the stones are used in the lower third of the pyramid up to a height of $49 \mathrm{~m}$. fig. 1

In the lower third of a pyramid $70 \%$ of stones are used. This can be illustrated with the help of the pyramid of Khufu: At a height of 49 $\mathrm{m}$ the remaining volume of masonry is just $30 \%$. 
fig. 2
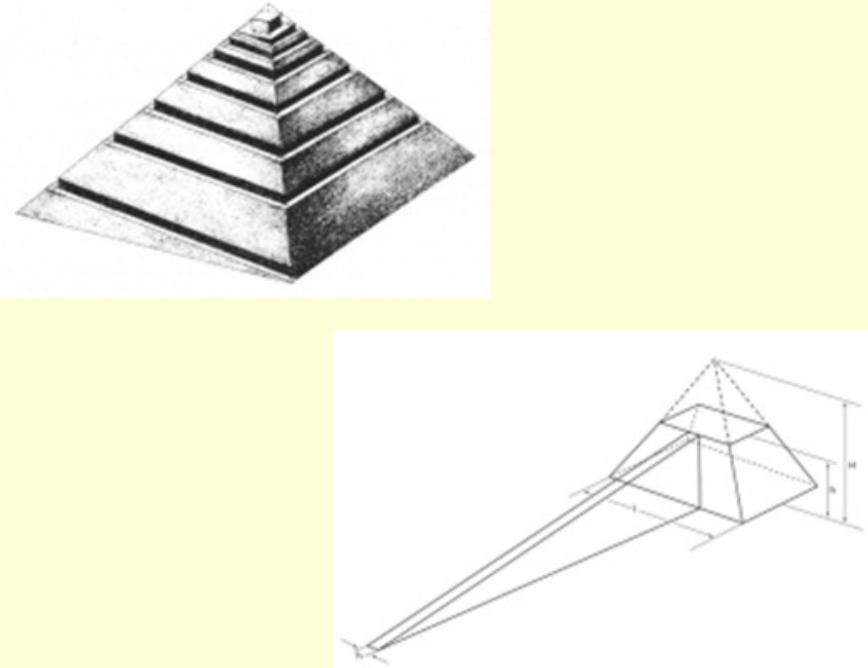

Conclusion No.1:

Construction time can only be reduced to a minimum by working on all four sides simultaneously using tangential ramps.

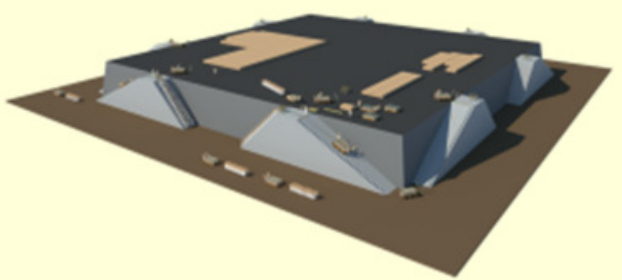

Transport of material using only one ramp always leads to a higher expenditure of time than a transport using several ramps simultaneously (fig. 2). Besides, many construction sites did not have room for such long ramps leading to the pyramid at a right angle.

fig. 3

This leads to conclusion no.1: A relatively short construction time is only possible by simultaneously building at all four sides of the pyramid (fig. 3). The number of ramps that are tangentially attached to the pyramid determines the construction time.

Extensive storage of stones at the construction site was not possible due to space constraints. For the Old Kingdom there is no archaeological evidence for lifting devices. The shaduf is mentioned for the first time in the New Kingdom. Therefore, a stacking of stones as a form of storage was out of the question.

This leads to conclusion no. 2: Manufacture of the stones, transport of the materials to the construction site and the construction of the pyramid itself had to be carefully coordinated at all times.

Today, we refer to such a system in which every step is precisely coordinated as "just in time manufacturing" (fig. 4). But this is by no means an invention of our time. This method was already employed in the construction of the pyramids of the Old Kingdom.

The time needed for the transport of the stones via steep tangential ramps to the current construction level was thus the determining factor with regard to construction time.

The amount of stones needed on a day-to-day basis could be manufactured in several quarries simultaneously. Archaeological evidence indicates that this kind of approach was used in the construction of the Pyramid of Khufu and the Red Pyramid. 
Similarly, transport from the quarries to the construction site could take place simultaneously via several transport ramps, as in the case of the Red Pyramid and the Pyramid of Khufu.

\section{Conclusion no.2: Just in time}

Manufacture of stones

as required at any one time

Transport to construc-

tion site

as required at any one time

Construction of

pyramid

Construction time was

determined by the

transport of the stones

via steep ramps.

Just in time
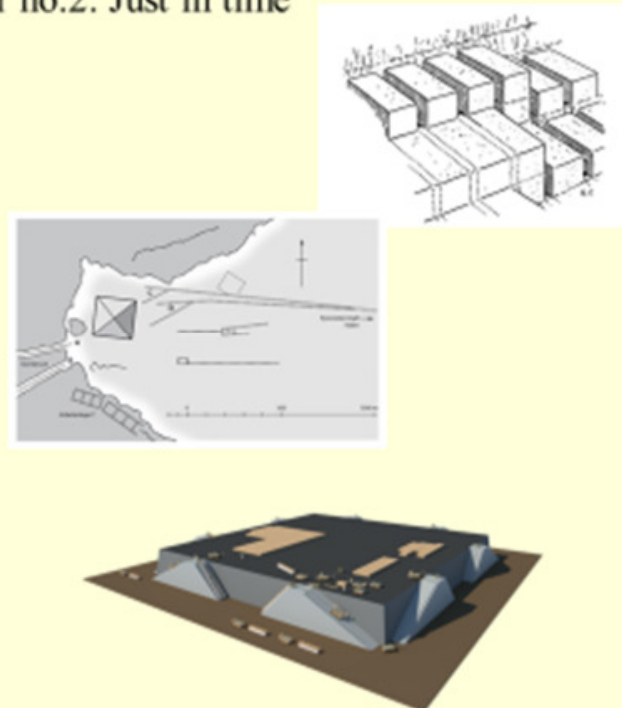

fig. 4

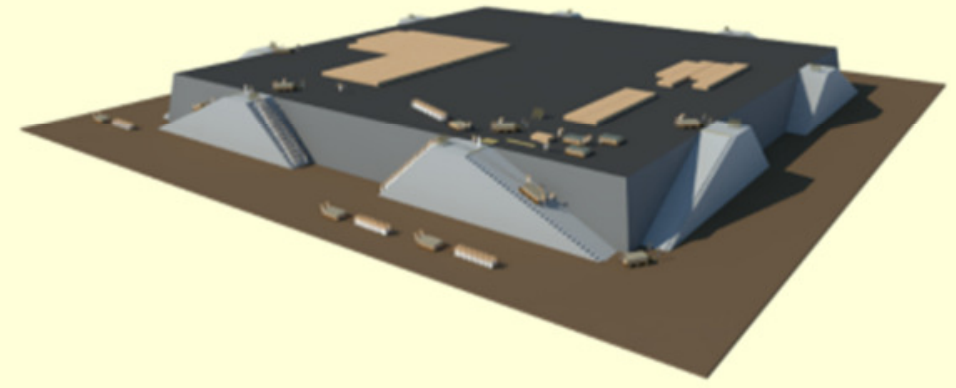

Placement of the stones of the individual courses fig. 5

The horizontal positioning and placing of the stones on the respective upper level of the unfinished pyramid could be carried out by a large number of workmen at the same time. Both work steps were only dependent on the amount of stones transported via the ramps and therefore not essential/crucial for construction time.

Conclusion no. 3: The transport ramps from the quarries to the construction site only had a maximum slope of 7 to 8 degrees as proven by archaeological findings. This prevented a sliding back of the stones during necessary breaks taken by the hauling crews or teams of oxen. Static friction always had to be higher than the downhill-slope force. 
fig. 6

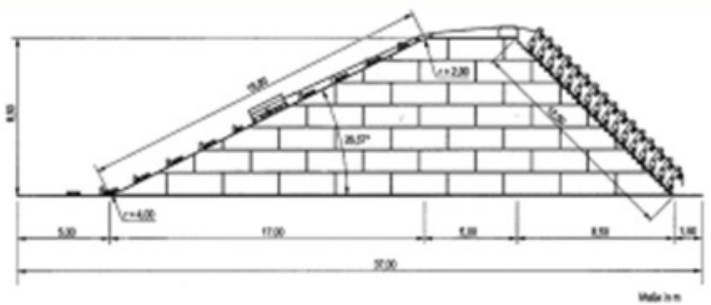

Ramp according to the measurements of the core steps of the Pyramid of Menkaure/Mykerinos (slope inclination 2:1)
Conclusion no. 4:

The tangential ramps on all four sides of the pyramid, however, could be significantly steeper due to the shorter hauling distances. Hauling breaks were not necessary (fig. 6).

\section{Some remarks concerning the building technique of the pyramids}

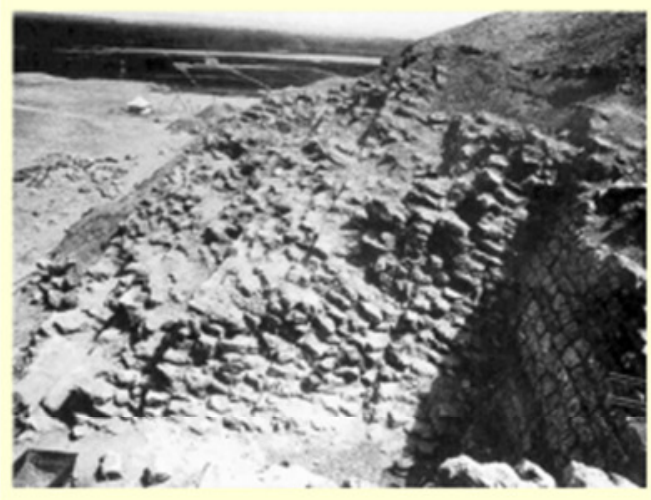

Construction principle of a layer pyramid (right) fig. 7

The building technique of the Pyramid of Djoser and that of Semenkhet in North Saqqara, that of Khaba in Saujet elArjan and those of Snofru at Meidum and South Dahshur is known in the modern literature as a "layers pyramid": several accretion layer leaning inward form the substructure of the pyramid (fig. 7). 


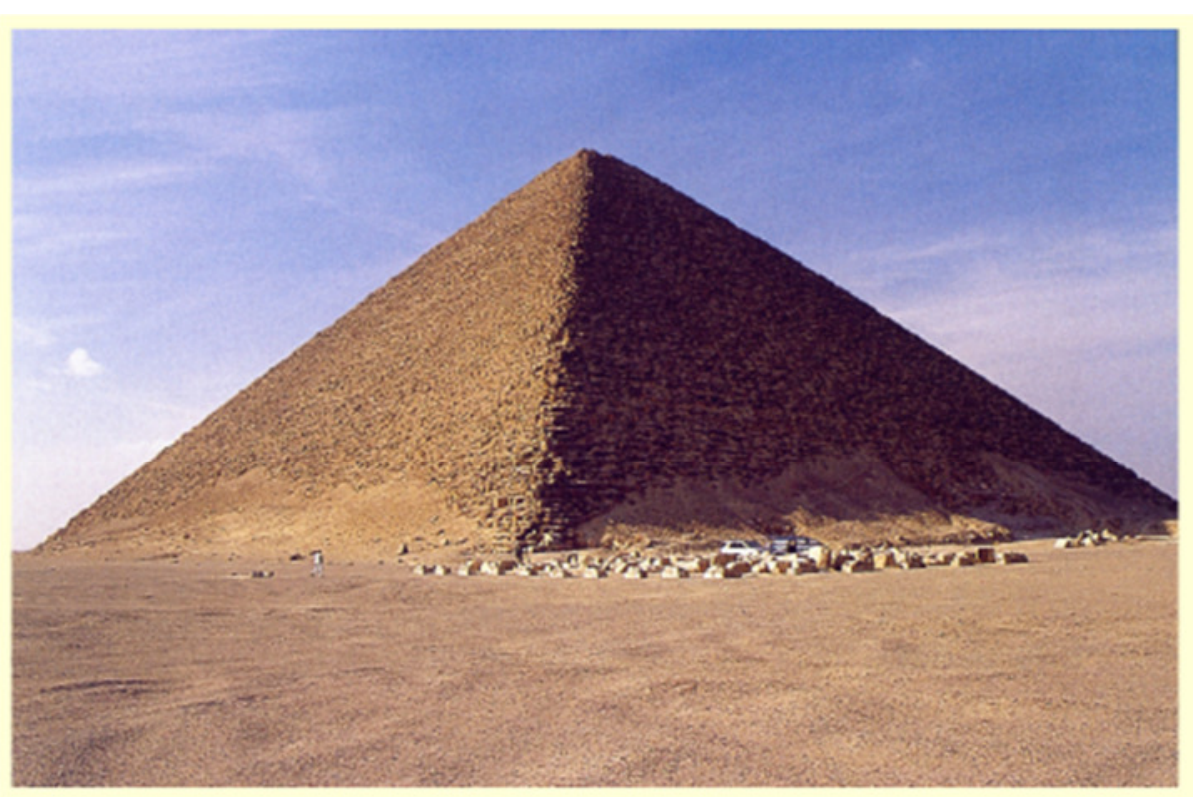

Red Pyramid in North Dahshur fig. 8

As a consequence of heavy earthquakes during the last 4000 years in Egypt, the pyramid at Meidum, the Bent Pyramid at South Dahshur and the Red Pyramid at North Dahshur among others suffered major structural damage. A high pressure on the underlying soil layer which was not always stable contributed to this damage. The weight of these pyramids per $\mathrm{m}^{2}$ is far higher than that of modern high-rise buildings.

The builders of Snofru therefore decided to lay the stones horizontally in the upper part of the Bent Pyramid, in the construction of the subsidiary pyramid to the Bent Pyramid as well as the Red pyramid. Furthermore, the Red pyramid was built with a reduction of the recess to 28 fingers per cubit, that is an angle of $45^{\circ}$ (fig. 8; Red pyramid at North Dahshur).

fig. 9

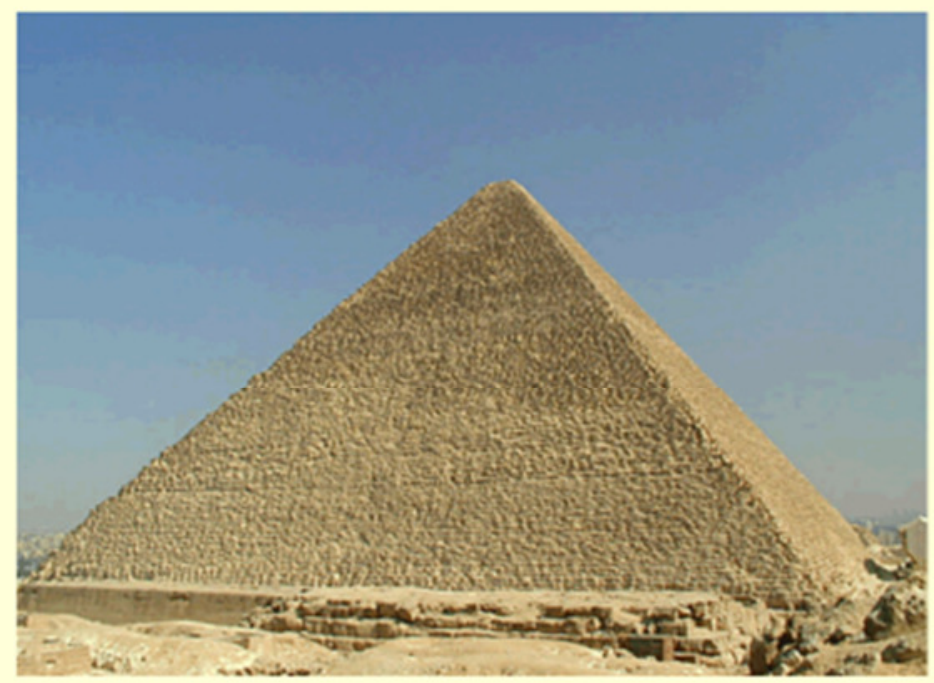

Pyramid of Khufu

There was a further change in the construction of the Pyramid of Khufu: As construction site the very solid nummulite limestone plateau near Giza was chosen. In addition, the pyramid was probably built with a substructure made of steps which was cased after completion. These are results of

examinations and measurements made by the author at the Pyramid of Khufu. 


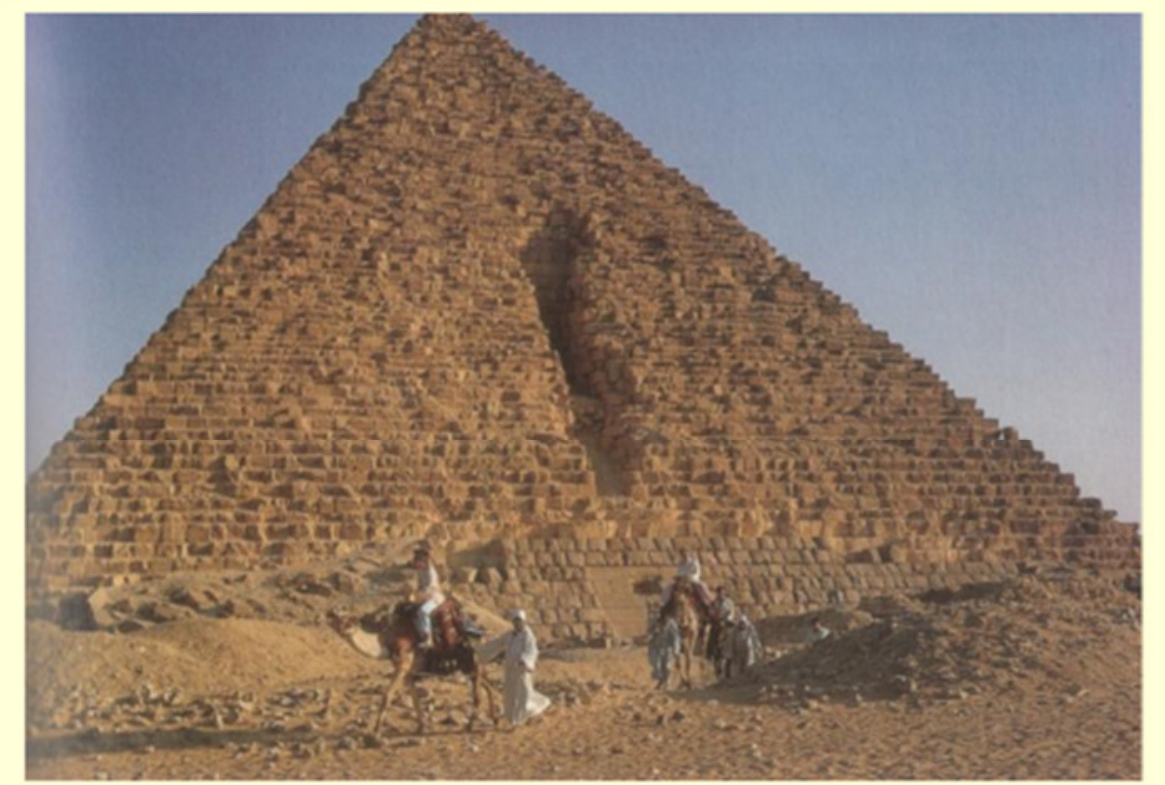

Pyramid of Menkaure fig. 10

This substructure consisting of steps is clearly visible in the great gash of the Pyramid of Menkaure which is up to $8 \mathrm{~m}$ deep and was cut open by the Mamelukes while searching for the entrance (fig. 10).

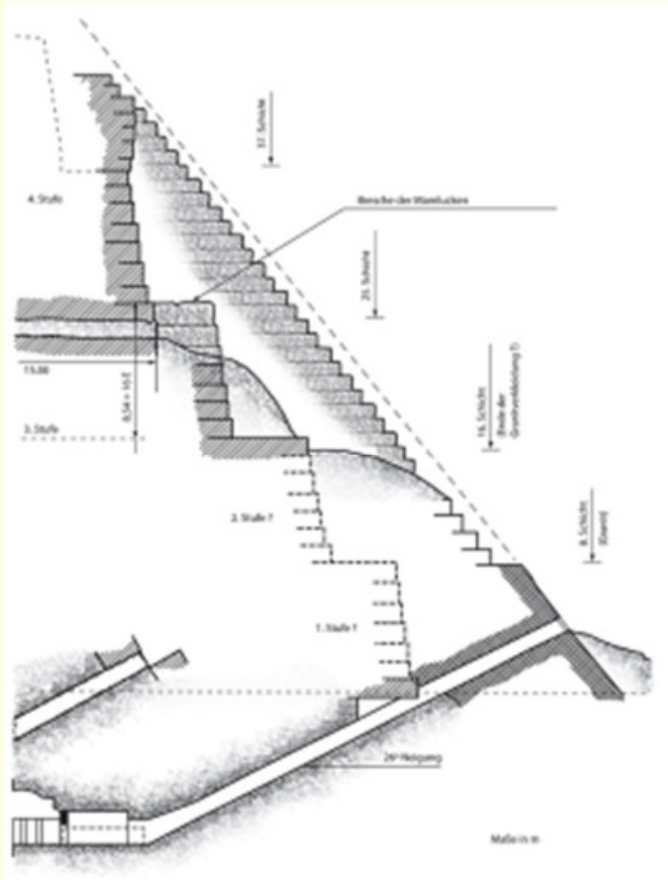

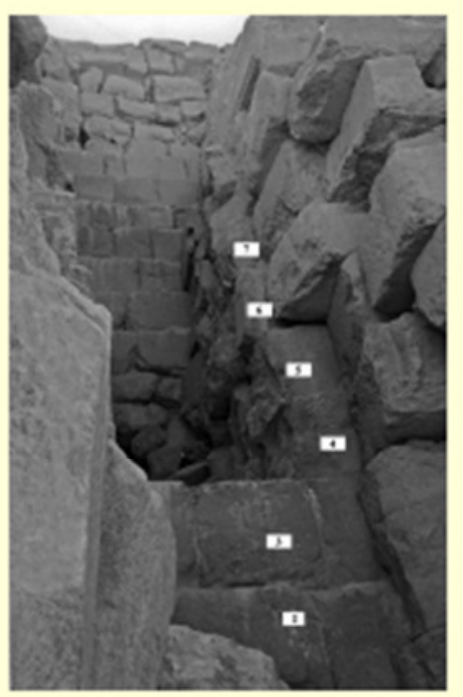

The seven courses of the third step of the inner core visible in the great gash of the Pyramid of Menkaure fig. 11

The core of the pyramid therefore is made up of rectangular stone structures, similar to Mastabas, getting smaller going up. The outer walls are slightly leaning inwards and are made of carefully worked stones; the inside is filled with stones of different sizes,

the spaces in between these stones are filled with sand and Tafla for an even distribution of pressure. An advantage of this building technique is that seismic shocks can be better absorbed than when inflexible masonry is used.

The second, third and fourth steps are clearly visible in a section of the northern side drawn by Maragioglio und Rinaldi (Fig. 11). 


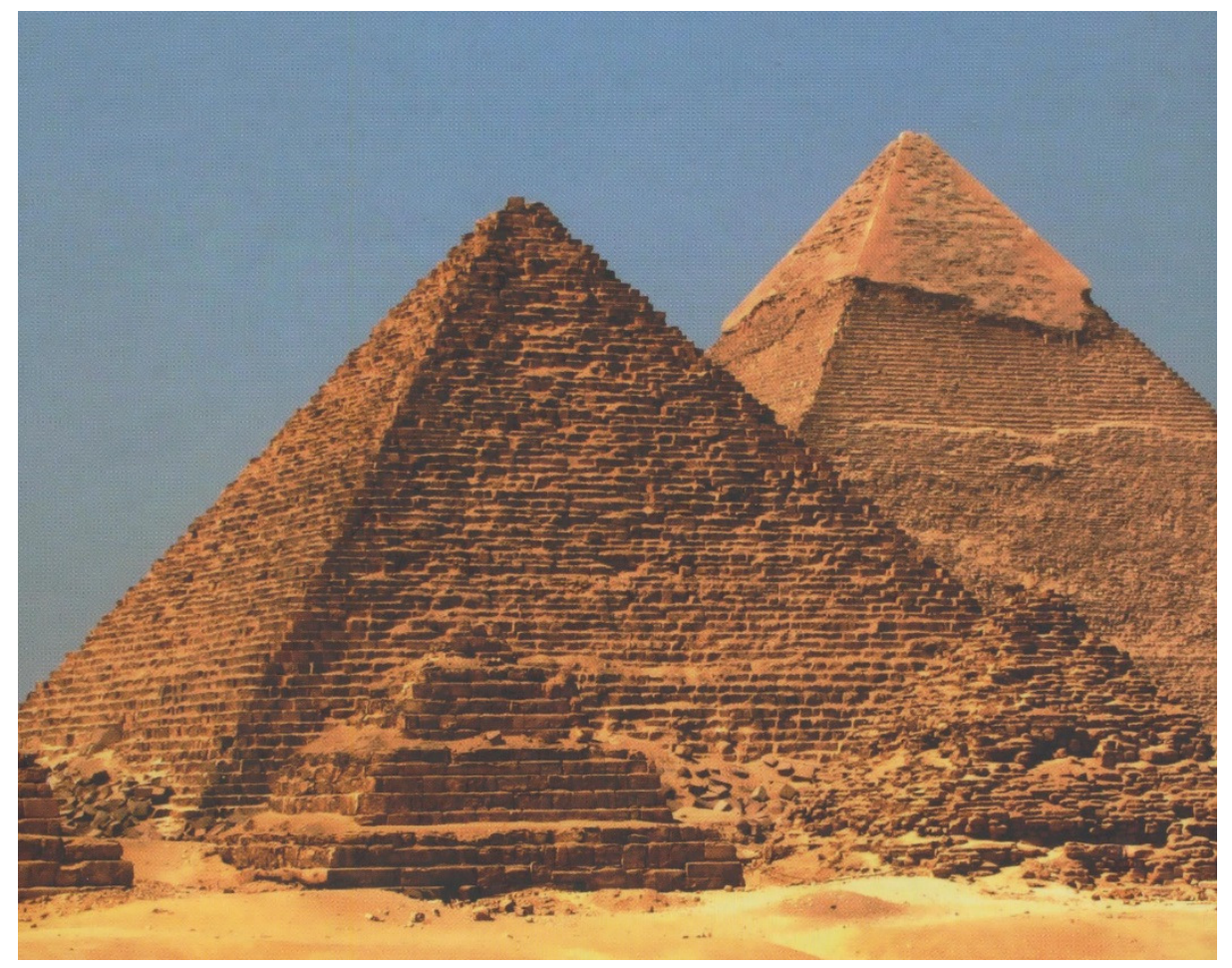

fig. 12

A substructure consisting of steps is also clearly visible in the queens' pyramids of Khufu and Menkaure (fig. 12).



Visible steps of the inner core of the Pyramid of Neferirkare at Abusir

fig. 13

The construction of this kind of substructure and the casing of the pyramids was consistent until the end of the 6th dynasty as is evident in the archaeological record (fig. 13).

Conclusion no. 5 is therefore: From the construction of the Pyramid of Khufu onward, the pyramids of the 4th to the 6th dynasty are clearly built as step pyramids. This designation is increasingly used in the modern literature. 


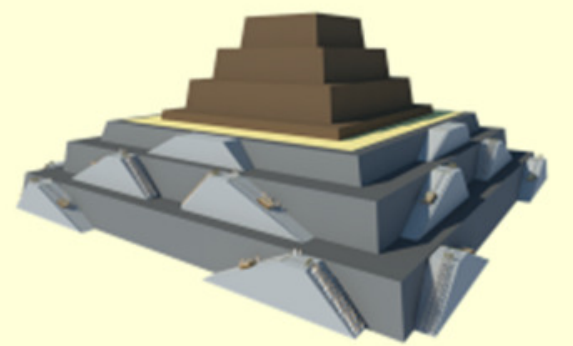

Construction of the casing with the help of auxiliary construction after the completion of the inner core

Dismantling of the auxiliary construction while simultaneously smoothing the casing fig 14

A further conclusion no. 6 is as follows: From an engineering point of view, the construction of the casing of the pyramid, the placing of the pyramidion and the subsequent smoothing of the casing from top to bottom could only be executed by using scaffolding or platforms that were

not attached to the casing (fig. 14). The workmen needed stable and save platforms to execute these tasks.

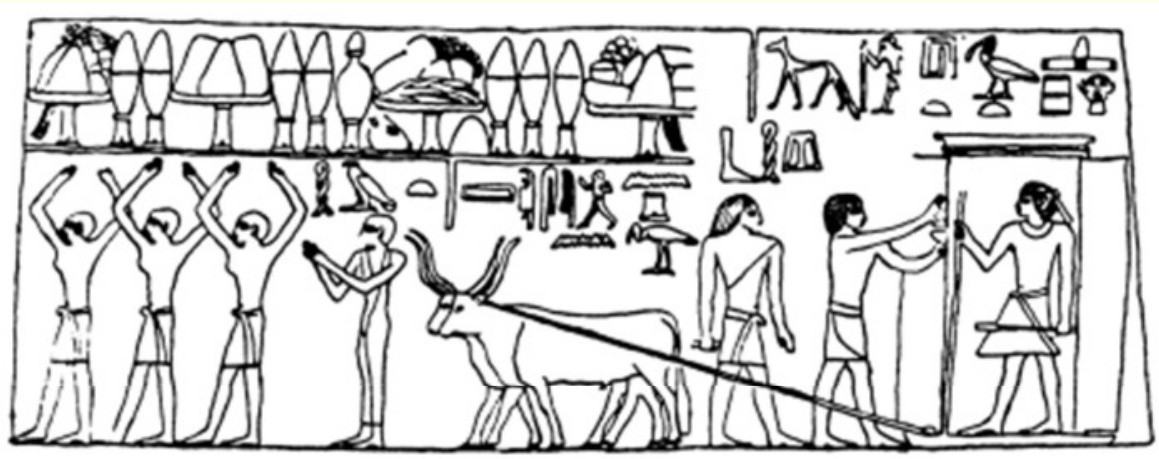

Transport of a statue with the help of a team of oxen, Tomb of Hetepherakhti, $5^{\text {th }}$ Dynasty

fig. 15

The 7th and last conclusion says that hypotheses concerned with the construction of the pyramids during the Old Kingdom can only include tools and devices as well as methods for procuring materials and means of transport for which there is archaeological evidence. These are chisels made of copper, dolerite pounders, wooden beams used as levers, transport slides (fig. 15), sloping levels and ramps, roller and deflection pulley (fig. 16), ropes as well as measuring sticks, angle gauges and sculptors cord (fig. 17). 

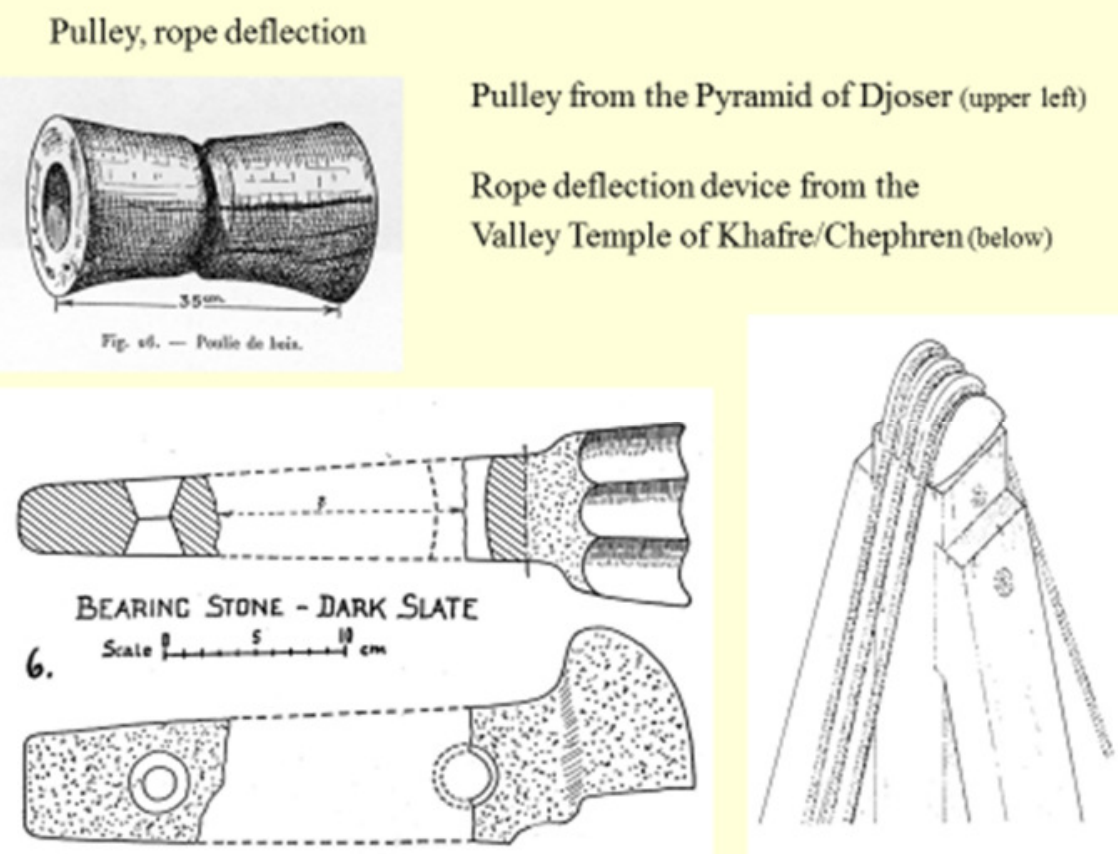

fig. 16
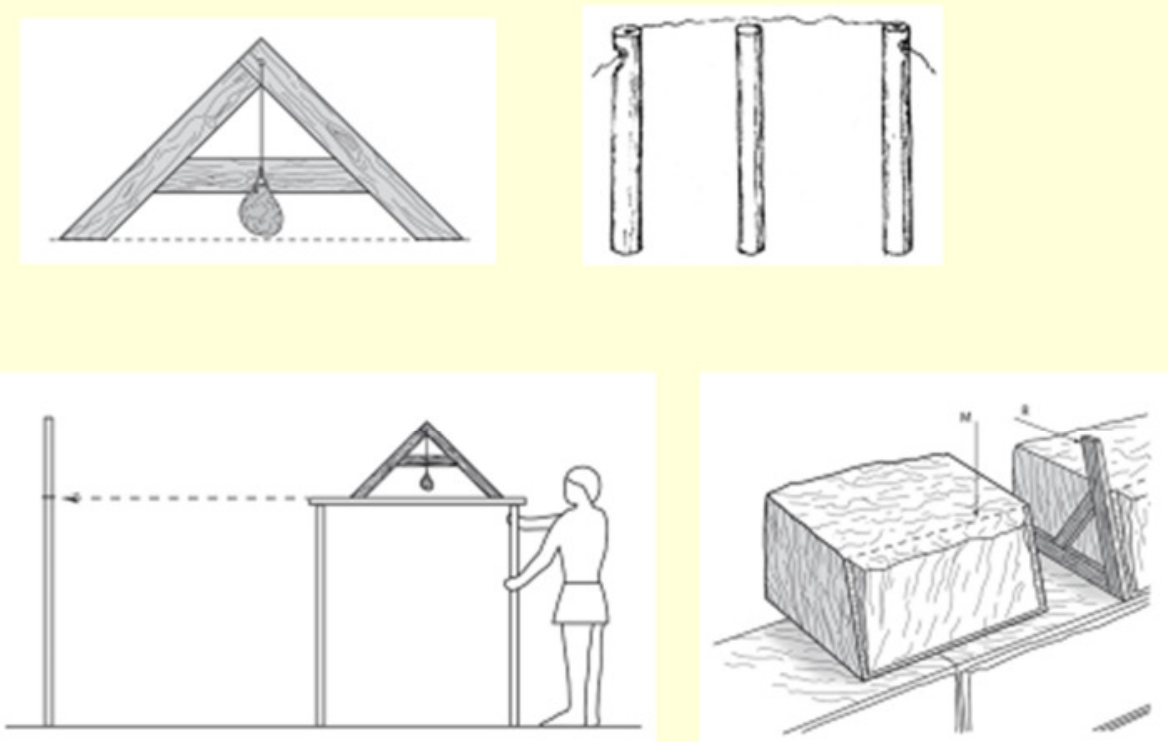

fig. 17

With these seven conclusions derived from the requirements of construction, the archaeological record and the time constraints, the essential prerequisites for the construction of the pyramids are defined. 


\section{Assessment of previously published construction hypotheses}

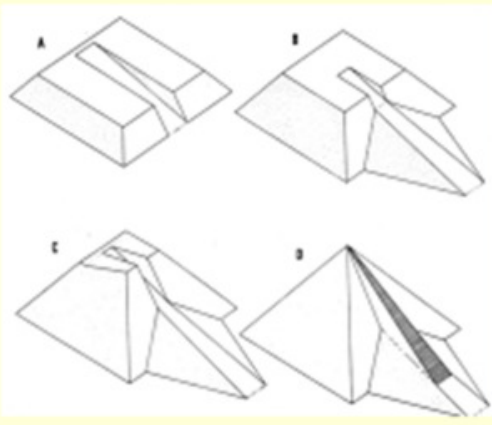

Suggestion by Arnold (upper left)

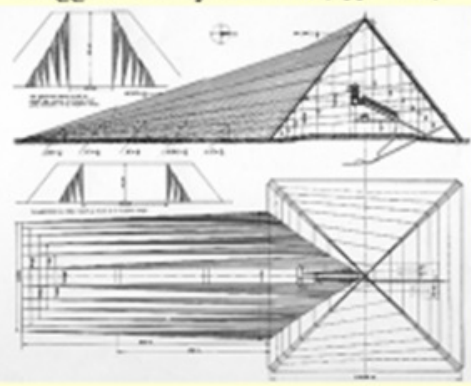

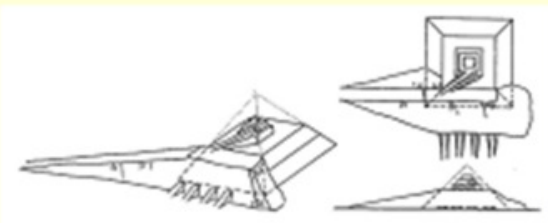
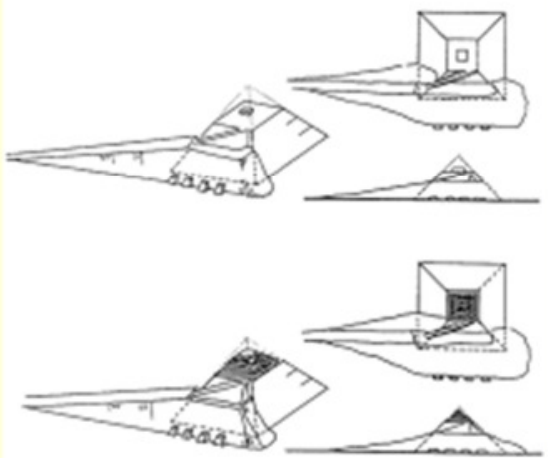

Suggestion by Lauer (lower left)

Suggestion by Stadelmann (upper right)

fig. 18

Previous construction hypotheses brought forward by Egyptologists like Arnold, Lauer and Stadelmann were based on ramps that ran towards the pyramid at a right angle. These have a lower transport capacity compared with tangential ramps. The construction of these ramps requires a huge quantity of building materials and a lot of space. A relatively short construction time cannot be achieved with these suggestions (fig. 18).

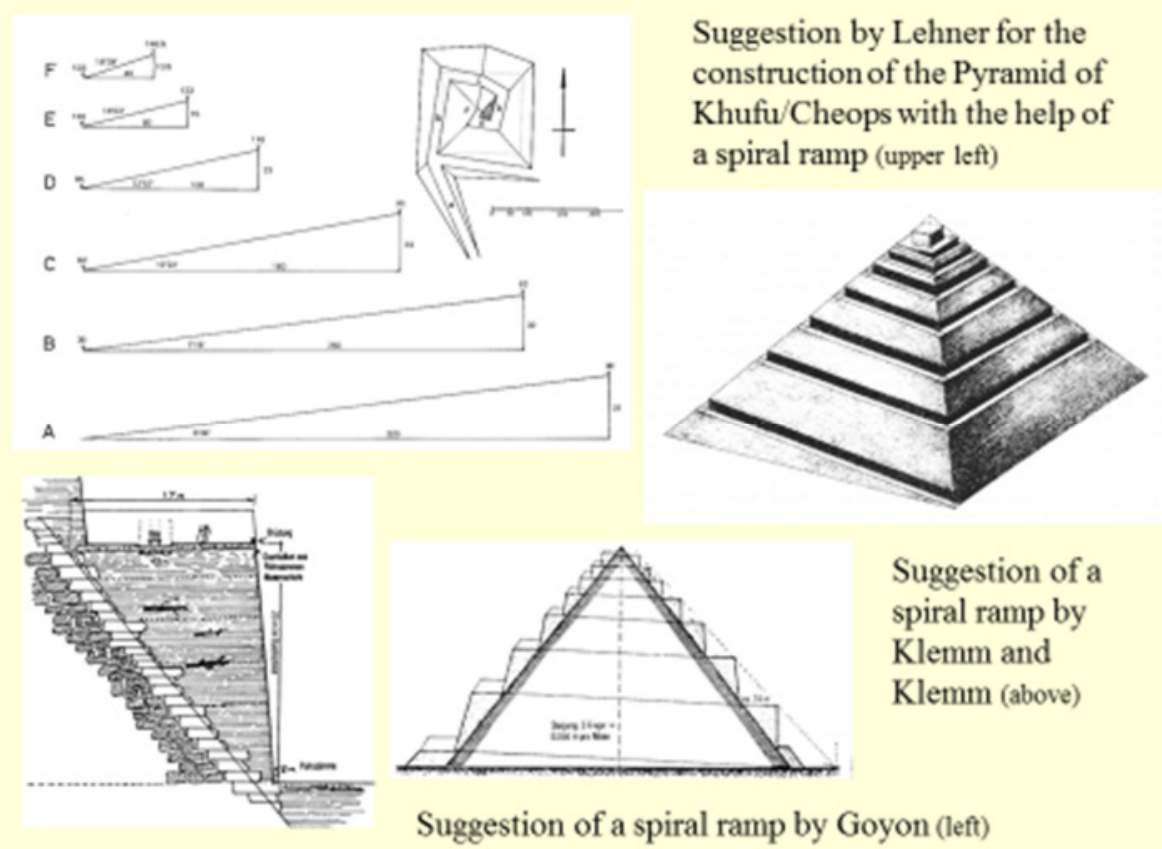

fig. 19

This also applies to the hypotheses by Goyon, Lehner and Klemm suggesting spiral ramps running around the pyramid base (fig. 19). 


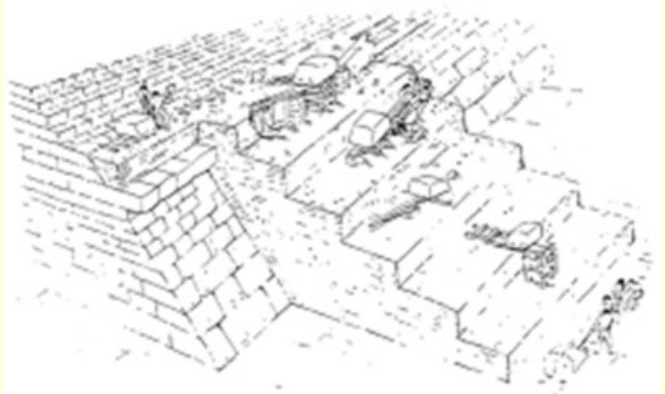

Levering of the stones as suggested by Isler (left)

Levering of the stones as suggested by de Haan (below left)

Construction using internal ramps as suggested by Houdin (below right)
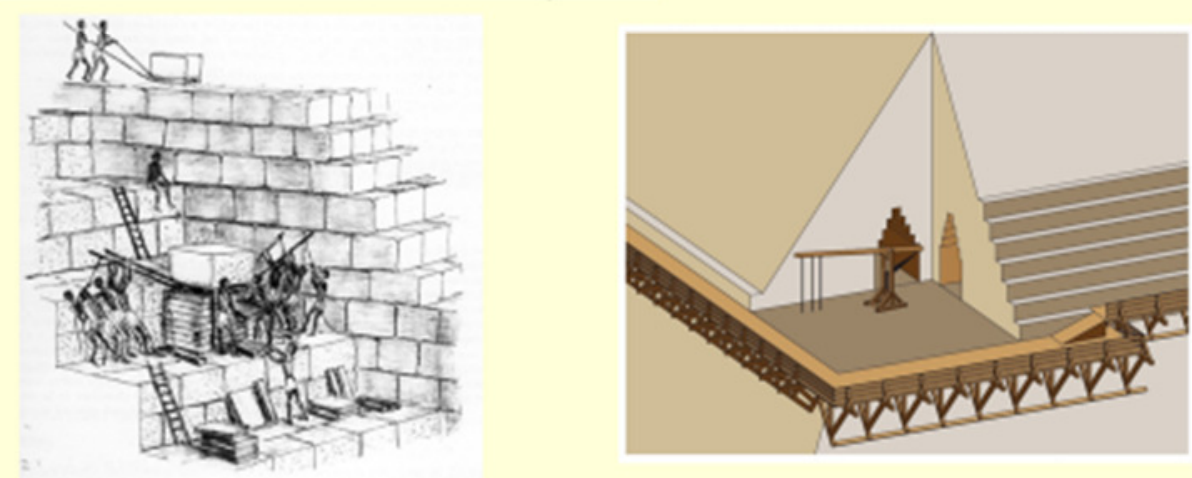

fig. 20

Further hypotheses, for example by den Haan, Houdin and Isler can be eliminated for a number of reasons (fig. 20).

Most of the hypotheses brought forward on the construction of the pyramids offer no feasible solution for the placing of the pyramidion and the smoothing of the casing of the pyramid. Furthermore, calculations regarding construction times are missing in most of the suggestions.

In addition, hypotheses brought forward by Non-Egyptologists, often disregard archaeological evidence regarding construction methods and tools used in the Old Kingdom, as stated in conclusion 7.

\section{Construction of pyramids using steep tangential ramps and auxiliary construction}

\section{The individual construction phases}

The individual construction phases will be illustrated using the example of the Pyramid of Menkaure:

After the completion of the base, the core masonry of the Pyramid of Menkaure was constructed with six steps. Using tangential ramps, the building materials could be transported upwards on all four sides simultaneously. After completion of the core masonry the ramps were built back (fig. 21). 


\section{Construction phases:}

\section{No.1: Inner core}
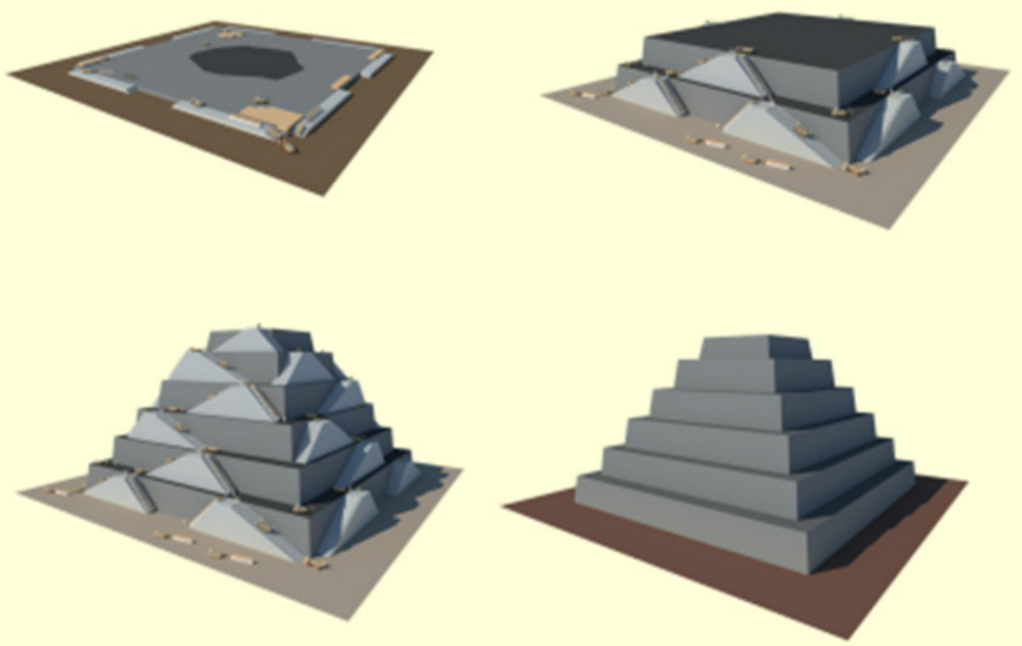

fig. 21

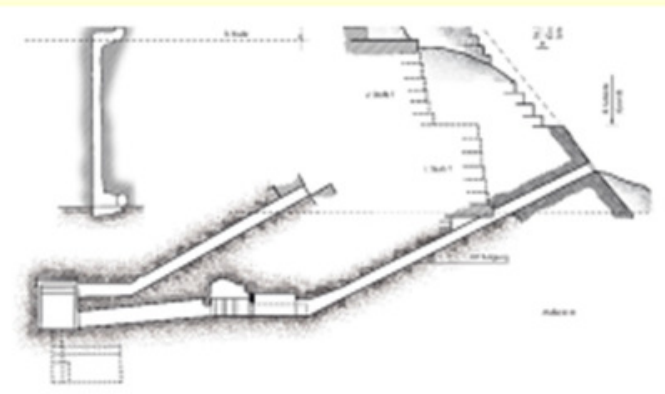

Passages of the Pyramid of Menkaure with a slope inclination of $2: 1$

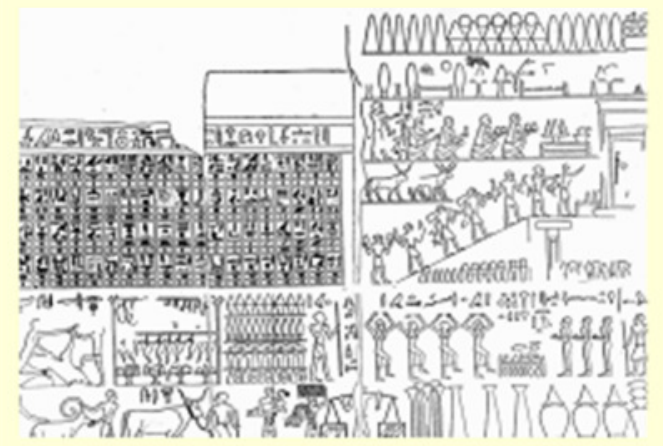

Schematic rendering of a ramp from the tomb of Debeheni in Giza, $5^{\text {th }}$ Dynasty

fig. 22

There is a lot of archaeological evidence from the Old Kingdom for steep ramps with an inclination of 1 (height) to 2 (base), corresponding to an angle of 26.5, for example at entrances to burial chambers as well as in illustrations in private tombs. Thus, this angle is supposed to be the state of the art at the time for the suggested tangential ramps (fig. 22).

The question, whether the core was constructed separately or whether construction phases 1 and 2 were carried out simultaneously, is still open. Results from examinations made by the author on-site suggest that the casing on the Pyramid of Menkaure was added to the steps of the core masonry with stones of different height. This supports a construction in two separate phases with additional expenditure for the deconstruction of the ramps. 
Construction phases no. 2:

Casing and placing of the pyramidion
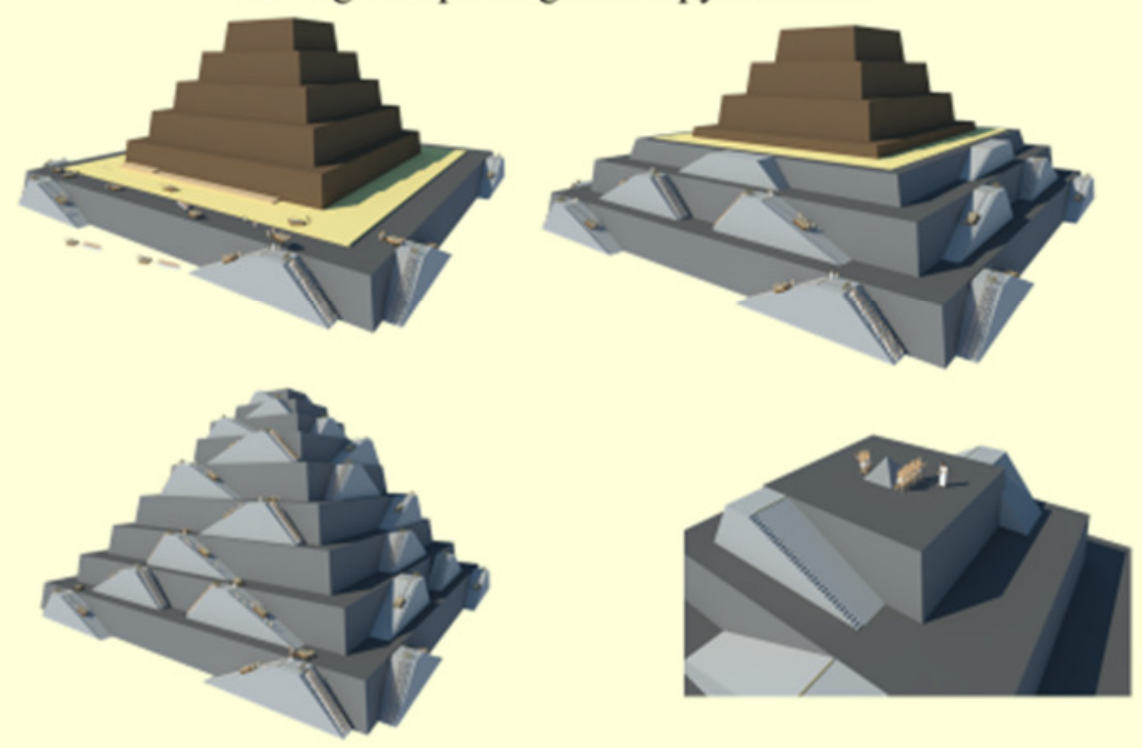

fig. 23

After completion of the core masonry its ramps are dismantled. Afterwards the casing is added. This is surrounded by a stepped auxiliary construction with additional ramps. The auxiliary constructions are supported against protruding stones of the not yet smoothed casing. In this way, the pyramidion can be safely transported via the ramps to the topmost platform and then moved onto the top of the casing horizontally (fig. 23).

\section{Construction phases no.3:}

\section{Smoothing of the casing from top to bottom}
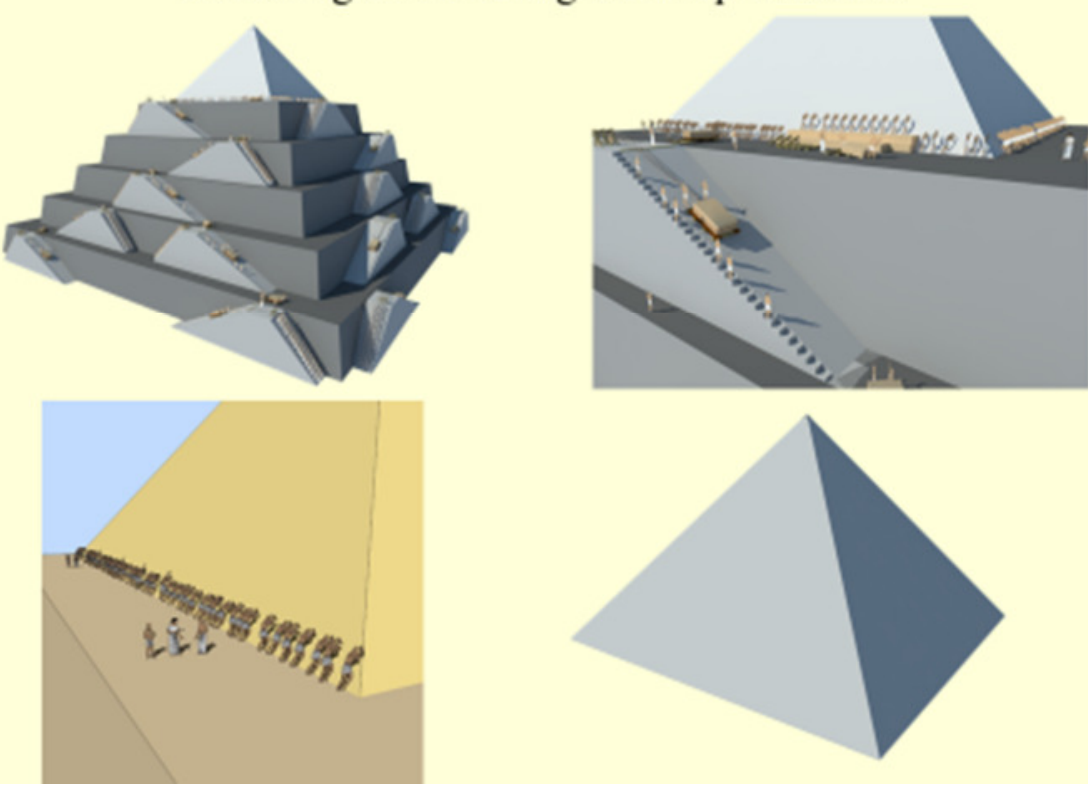

fig. 24 
During the subsequent third construction phase, the ramps are dismantled from top to bottom. At the same time the casing is smoothed thus minimizing the risk for the workmen who are assigned to this task.

\section{Calculating construction time}

\section{Calculation of the construction time}

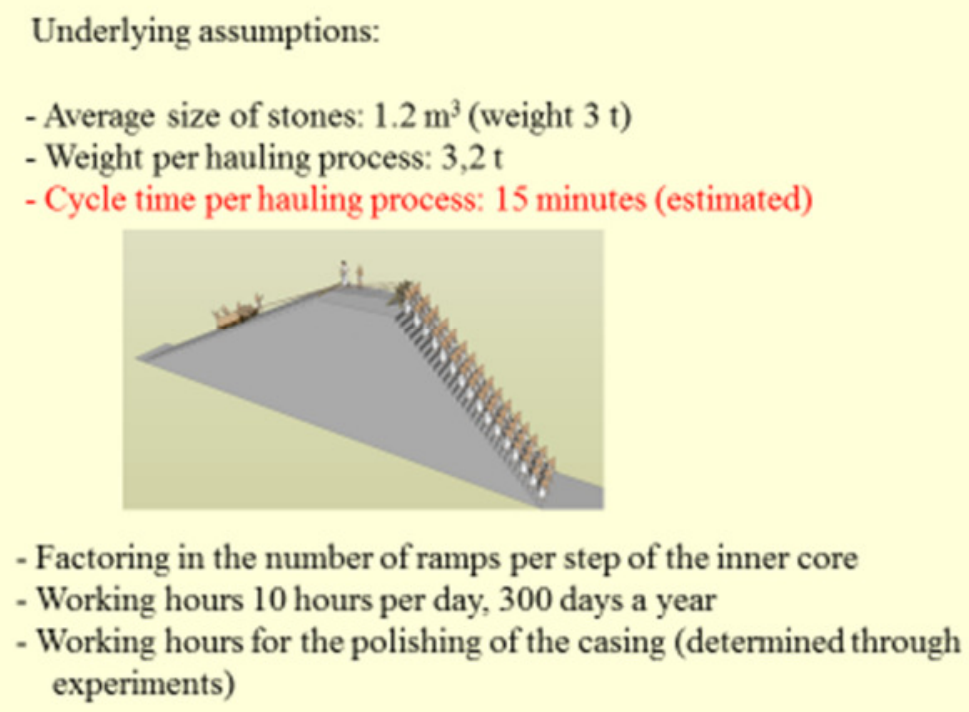

The following assumptions are made: average size of stones $1.2 \mathrm{~m}^{3}$ (weight $3 \mathrm{t}$ ) and weight per hauling process 3,2 t. Cycle time for one hauling process via the ramps (fig. 25) is estimated at $15 \mathrm{~min}$ and daily working hours of 10 hours in shifts on 300 days a year are assumed.

Unfortunately, the cycle time of 15 minutes which was settled on after discussing the issue with construction engineers could not yet be verified. However, the actual construction time of the pyramid is heavily determined by this. A proposal for an experimental trial in 2014 was submitted to the German Research Foundation (DFG) but sadly rejected.

Construction time for the core masonry, the casing and its smoothing, the construction and dismantling of the ramps as well as the preparatory works for the Pyramid of Menkaure according to this method amounts to approximately 4.8 years (fig. 26).

A comparative calculation for the Pyramid of Khufu and the Red Pyramid adds up to construction times of 22.5 and 18.7 years respectively. In doing so, construction for the Red Pyramid is assumed to have started in the 15th year of Snofru's reign.

The construction times calculated for the three pyramids are thus consistent with the length of the reigns of these kings: Snofru 35 years, Khufu 23 years and Menkaure - most recently found to have been 6 years (following Kauss and Warburton). 
The construction time for the Pyramid of Menkaure using the method described amounts to

$$
\text { c. } 4,8 \text { years. }
$$

A comparative calculation for the construction times of the Pyramid of Khufu and the Red Pyramid results in

$$
\text { 22,5 years (Khufu) and 18,7 years (Red Pyramid) }
$$

$\begin{array}{lll}\text { Reign of the kings: } & \text { Menkaure } & \text { 28 or 6 years respectively } \\ & \text { Sneferu } & \text { 35 years } \\ & \text { Khufu } & \text { 23 years }\end{array}$

The construction times are thus consistent with the length of the respective reigns.

\title{
Concluding remarks
}

\begin{abstract}
The proposal for the construction of the Old Kingdom pyramids using steep tangential ramps and an auxiliary construction was published in 2008.
\end{abstract}

Up until now, no scientifically substantiated contradiction has been published.
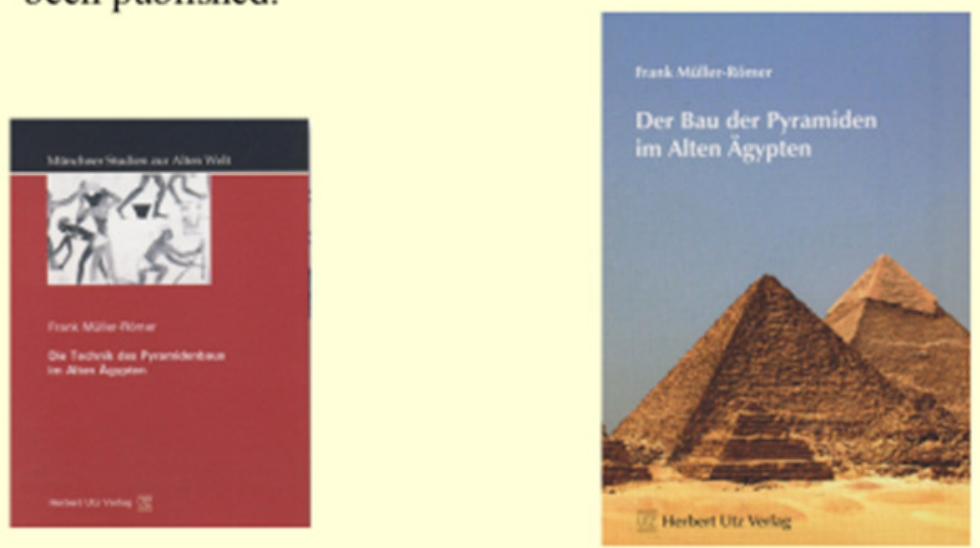

The suggestion that pyramids in the Old Kingdom were built using steep tangential ramps and auxiliary constructions was from author first published in 2008 and since then has been presented and discussed in various publications.

Up until now, no scientifically substantiated contradiction has been published. 